\title{
HIGHER EDUCATION METHODOLOGIES: FROM URBAN PLANNING TO MATHEMATICAL ISSUES
}

\author{
A. Virtudes, I.I. Rodrigues, A.M. Simões, R. Serôdio \\ University of Beira Interior (PORTUGAL)
}

\begin{abstract}
This article will be focused on higher education learning and teaching methodologies, based on the experience of the Master Degree in Civil Engineering at the University of Beira Interior, in Covilhã (Portugal). It aims to present the results of the practises used by scholar of urban planning and mathematical issues, both regarding the civil engineering research field. Actually, there are some similarities in between the research process features of urban planning domain and mathematics field in order to promote the students' success.

In fact, these both scientific subjects follow analogous tasks in their research processes, not only regarding the same starting point which is the definition of the research problem, but also observing the final phase, which is based on the findings of results, or the proposed solution.

It joins scholars from the department of civil engineering and architecture, experts in spatial analysis and scholars from the department of mathematics of the University of Beira Interior (UBI).

One case study will be presented as an example and pioneer research of the application of these methodological approaches. It will be focused on the urban planning experiences, associated with postgraduate teachings. It is related to a PhD thesis in Civil Engineering focused on urban planning issues.
\end{abstract}

Keywords: Higher education, research methodologies, urban planning, mathematics, postgraduate teachings.

\section{INTRODUCTION}

This article is focused on research methodologies used at the civil engineering research field focused on the urban planning and mathematical issues. It is the result of an interdisciplinary approach gathering scholars from mathematics and urban planning subjects, responsible for teaching at the civil engineering degree, and $\mathrm{PhD}$ candidates in civil engineering having the urban planning as the research topic. In fact, the research methodology framework in many aspects is analogous in between the mathematics domain and the urban planning domain. These similarities are present on the phases of the research process which are used on these both scientific domains. Despite of the differences in terms of contents of the research tasks, the organization of the research process in really similar.

On the one hand, both subjects are basing their investigation tasks, starting with the identification of a research problem that should be solved by the researcher, as the first step. On the other hand, both subjects are organizing the research process based on several steps until the final phase which is the solution proposed in order to solve the problem in the case of mathematics or to mitigate the problem in the case of the urban planning.

The key outcomes of the teaching methodologies at Civil Engineering at UBI, show that the main changes in teaching practices are based on aspects such as the reduction of the number of students working in each group, or to have extra hours of classes in the domain of math [1].

\section{TEACHING METHODOLOGIES}

\subsection{Research process framework in urban planning}

\subsubsection{General aspects}

There are several ways of structure the research process regarding the urban planning domain. However, all of these different perspectives have a similar approach which is to define a starting point 
with the identification of a research problem, something that is not working well at the territorial dimension which is the study object.

Another similar aspect is the fact that the final step of the research is to propose the solution or solutions in order to diminish the starting point problem.

In between these two phases, the first and the last, the research process can very according to the features of the analysed case study, the period of time defined for the analysis, or the scale of the investigation in territorial terms. Some authors, in [2], are suggesting that there are at least two analysis phases at the urban planning research, which are the following: $1^{\text {st }}$ - data collection or retrieval. The referred author says that this step is "purely dedicate to research and laborious data retrieval and documentation" [2]; $2^{\text {nd }}-$ mapping the phenomenon that is being studied. This author argues that this phase has a "preliminary importance" [2]; These two phases can be understood as being part of the research process of a case study of urban planning, in between the identification of the research problem or the territorial phenomenon that is going to be studied, which is the $1^{\text {st }}$ step and the proposed solution which is the last step.

Despite of the different approaches, tasks or their contents defined to the research process as a whole, there is a common structure that could be followed as reference in the urban planning investigation. Therefore, the urban planning research could be seen has a process which is based on six main tasks, according to the following phases (Figure 1):

- $1^{\text {st }}$ - identification of the research problem or the territorial phenomenon, including the two tasks listed below:

○ case study;

○ pioneer examples;

- $2^{\text {nd }}-$ literature review;

- $3^{\text {rd }}$ - data collection or retrieval, including the following four tasks:

- statistics data;

o on-site analysis;

o documentation of the spatial planning instruments and ordinances rules for the case study area;

○ inhabitants' surveys promoting the public participation;

- $4^{\text {th }}$ - diagnosis of the current situation mapping the phenomenon;

- $5^{\text {th }}-\mathrm{A}$ kind of cost-benefit analysis which refers in the urban planning domain to the framework of the problems and potentialities of the case study area, in order to find the solution which will be focused on suggestion to diminish the problems and suggestions to develop the potentialities;

- $6^{\text {th }}-$ Final solutions or strategies.

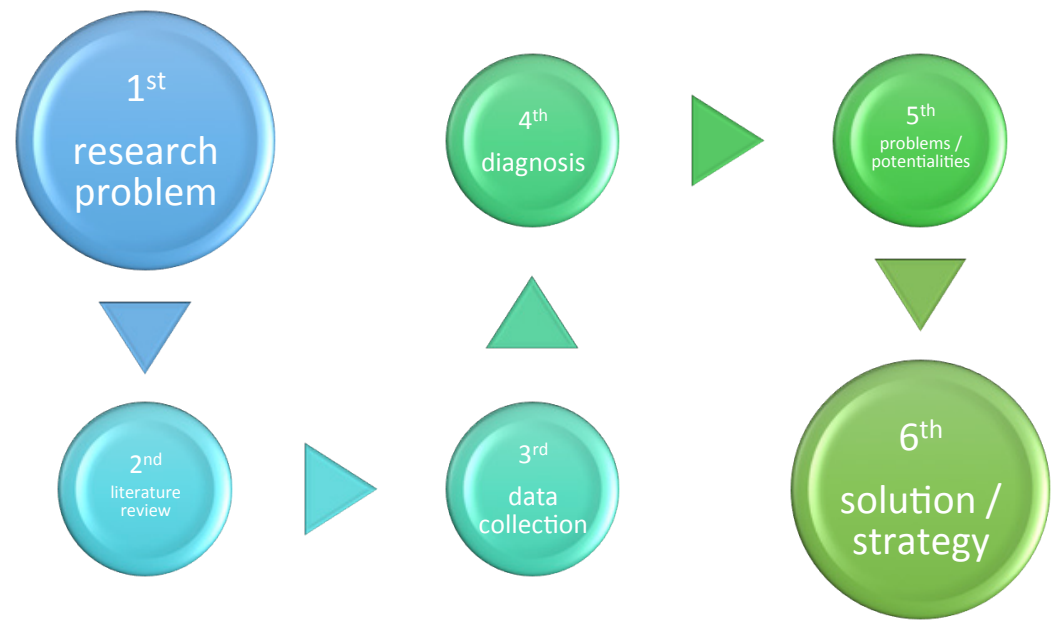

Figure 1. Research methodology tasks in urban planning process. 
The next section will be focused on the presentation of one case study of the application of the urban planning methodologies, having has example the Portuguese territorial context. This case was developed at the Department of Civil Engineering and Architecture of the University of Beira Interior. It is related to postgraduate teachings, based on a $\mathrm{PhD}$ research.

\subsubsection{The case of a PhD research in civil engineering focused on spatial planning issues}

This case study is part of an ongoing PhD Thesis in the domain of spatial planning, on the behalf of the doctoral programme of Civil Engineering, having the territorial analysis has the main research line.

It has as a starting point a step based on the literature review focused on the rethinking of the local governance, and the need for its efficiency, regarding the management of the building and urbanization projects, by the municipal authorities. The governance at the municipal level of the public administration, concerning the spatial planning process is generally inefficient, triggering several failures such as in terms of communication and information to the citizens in general. This problem happens either to the authors of the building and urbanization projects or to the land owners. In fact, the literature review that the governance depends on "the process of transmitting information through the communication technologies between authorities and citizens" [3].

In order to better understand this issue, there is the need of reflecting on the unsatisfactory conditions in which the governance regarding the spatial planning management is happening at the local level.

The contents of the spatial planning instruments and of the building and urbanization ordinances should be more available and disseminate among the public in general and in particular considering the authors of the building and urbanization projects and the land owners. This dissemination could be called a "new public service" [4] which will serve as an alternative for the "old public administration" as a "new public management" and a "new public service". This new approach aims to reaffirm the values of democracy, citizenship and public interest as prominent aspects of any public administration, beginning with the recognition that the existence of an engaged and enlightened citizenship is critical to a more democratic governance.

According to the same author, this new model of public administration design should be materialized in the form of an interactive governance as a participatory management trend. This implies sharing and disseminating information in order to transform the stakeholders of the society (including the public and private realms) "allies in the search for better results, both regarding administrative performance and increasing democratic legitimacy" [5]. In this sense this research has defined has its $1^{\text {st }}$ step the identification of the research problem, which is the governance inefficiency regarding the spatial planning process at the local level, considering the building and urbanization projects. Therefore, the main objectives of this investigation are based on the goal of finding strategies in order to reach a new spatial planning model in terms of governance at the local scale, in order to promote a better efficiency of the management process of the building and urbanization projects.

Many authors are spending ink advocating that a better information and communication to the citizens is a requirement of the governance in parallel to the increasing of the responsibilities in the decisionmaking process [6].

After a $2^{\text {nd }}$ step focused on the literature review and a $3^{\text {rd }}$ based on the data collection, this research has as phase $4^{\text {th }}$ the goal of creating a catalogue with all the types of building and urbanization projects, that could be a reference at the urban planning process at local level. This catalogue is a key task in this research because of the following reasons: first of all, it represents a synthesis of the previous phases, given that it will represent all types of building and urbanization project that could be supervised and approved by local authorities; secondly because it can be used as a reference manual in all the 308 Portuguese local authorities (all over the country including Azores and Madeira islands and the continental territory), i.e. the municipalities, given that all the types of projects are represented in it.

The $5^{\text {th }}$ methodological step of this research is related with the proposal i.e. the solution in order to diminish the identified research problem, contribution to increase the efficiency of the urban planning governance. This solution will be a guide of good practices showing how the several types of building and urbanization projects should be in order to respect the spatial planning ordinances, turning more efficient the municipalities governance in terms of territorial management. 


\subsection{Research tasks in mathematics issues}

\subsubsection{General aspects}

This section will be focused on the discussion about the definition of a set of research tasks in the mathematical domain, the different types of mathematical tasks and how these tasks are going to have influence at the learning of mathematics. The referred tasks are called investigative tasks. Therefore, among other aspects, the students' learning of mathematics issues, is related to the way how the scientific contents are transferred to them, the way how the activities are taking place in the classroom, and with the sort of works including practical exercises that are proposed to them by the teacher.

The research tasks are elaborated and given to the students by the teachers, and they are considered by many authors as one of the key pillars in the teaching-learning process. In this sense Pires [7] argues that the development of a mathematics class is influenced by several factors. For the author, these factors that greatly influences a "good" mathematical activity are the following: the organization and the affectivity in the academic institution; the social environment and the family perspective of the student; the way how the students think and approach the different contents of mathematics; the perception that students have on the academic institution; the way how the scholars are teaching and working on the various mathematical contents; the elaboration of practical exercises and tasks for students. According to the previous idea, the scholar should develop several tasks according to the level of knowledge of the student and he/she should be focused on a mathematics approach that has real and significant basis.

The tasks to be proposed should have intuitive and inductive characteristics, in order to allow the student in a quick way, to be able to identify some known mathematical patterns which will allow him to reflect and to expose his/her ideas, giving him/her the pleasure in finding the solution.

The way how the scholar is going to define the research tasks and to encourage the students' achievements, is very important in order to enable a meaningful learning activity among the students.

According to some authors in [8], a research task has four dimensions, which are the following: its degree of difficulty; its structure; its context; and the time that is required for its acquisition. Despite of the importance of all these aspects, this paper will explore deeply the first two dimensions of the research tasks; their structures and their degrees of difficulty; which are linked to four types of mathematical tasks, according to the same reference, which are the following features: exploration, exercise, problem and research.

Regarding the exercises and the problems, these two aspects are tasks that have a similar nature and with the same structural dimension, with the exercises having a lower level of difficulty in relation to the problems. Regarding the research and the exploration they are structurally open tasks. However, the explorations are easier than the investigations.

For other authors ([9]) the different types of research tasks strongly contribute to the learning process, as referred to in the following citation: "Tasks of a more closed nature (exercises, problems) are important for the development of mathematical reasoning in students, since this reasoning is based on a close and rigorous relationship between data and results. Regarding the tasks of a more accessible nature (explorations, exercises), they allow all students to achieve a higher degree of success, contributing to the development of their self-confidence. About the tasks of a more challenging nature (investigations, problems), they are indispensable for students to have an effective mathematical experience. Finally, the open tasks are essential requirements for the development of certain particular skills of the students, such as autonomy, the ability to deal with complex situations (...)".

\subsubsection{Methodological approaches in mathematics}

In terms of methodological approaches in mathematics, the concepts of problems and investigations are similar, but they perform different functions. On the one hand, the term "problem solving" is related to the activity in which the solution is sought for a certain problem, using various procedures. On the other hand, the term "research" refers to an activity that seeks to respond to certain situations in a broader way. According to this idea, Polya (1977, cited by Pires [7]) says that: "The resolution of a problem involves: (1) understanding the problem; (2) design a resolution plan; (3) execute the plan; (4) reflect on the work done." (Figure 2) 


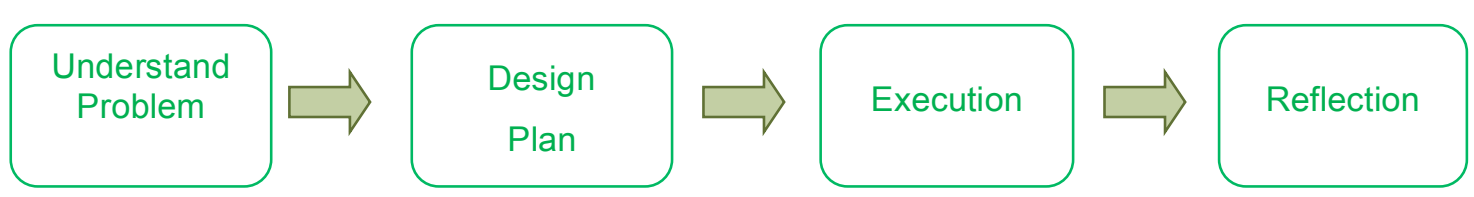

Figure 2. Steps of the resolution of a mathematical problem.

Other authors such as Ponte, Oliveira, Cunha and Segurado (1998, cited by Pires [7]) stated that: "A research has a diverse approach, including: (1) formulating the question to investigate; (2) to formulate conjectures on this issue; (3) testing the conjectures and eventually reformulating them; (4) validate and communicate the results." (Figure 3)

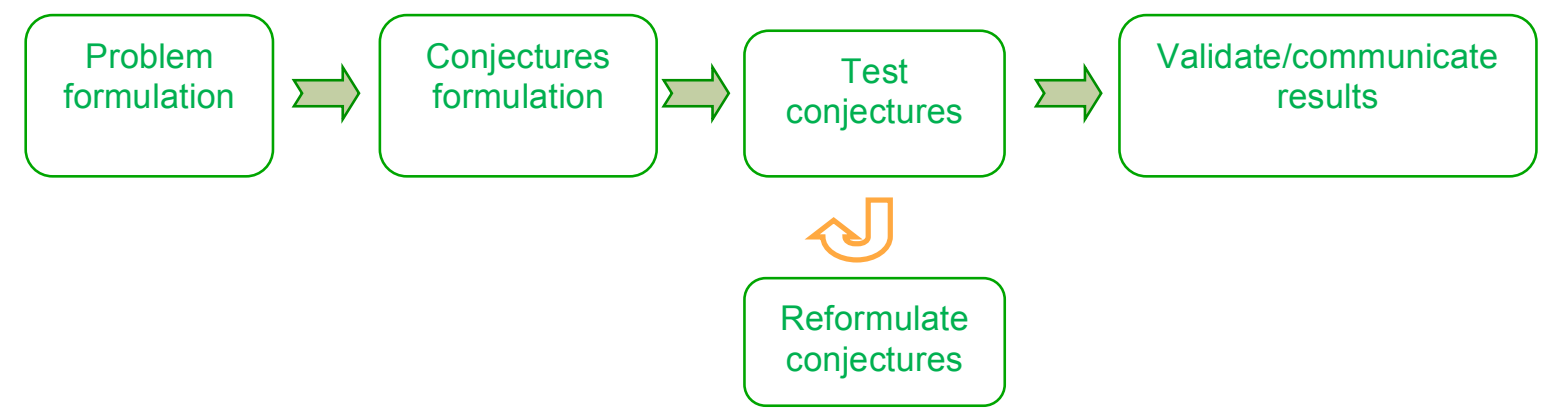

Figure 3. Diverse approach of a mathematical research.

The different types of tasks are related to each other although it is not easy to distinguish them. Ponte [8] also emphasizes that a certain task can be at the same time an exploration or an exercise, independently of the level of knowledge of each student.

Considering the mathematical scientific field, the different types of research tasks help and enable students towards a better understanding of mathematics issues, challenging them to renew and to innovate their mathematical ideas, motivating them to further researches, to design new strategies and to develop their way of thinking.

One aspect of utmost importance regarding the scholar role is the differentiation of the several tasks, which are recommended to the students, related to the nature and the social environment in which the academic institution and the student are inserted. Thus, the students can realize the application of mathematics in their social context. The scholar should propose to the students, tasks that encourage them to discover new mathematical results, looking for solutions that they can perceive what they are doing and why are they doing that, motivating them in order to have a special taste for this subject.

According to the same reference, Ponte [8] emphasizes that, in addition to the diversity of the research tasks to be proposed to the students by the scholar, they must have a logical and organized sequence in order to allow the students to duly acquire mathematical concepts, to understand the used methods and formulas, knowing how to relate them properly. In this way, there is the necessity of applying the investigative tasks in the classrooms, allowing the students by themselves to look and to try to find the right solutions, understanding how mathematics is constructed.

In summary, given that the mathematics is mainly learned by practicing and not simply by looking at concepts, the research tasks strongly contribute to the learning process of mathematics.

Authors such as Braumann and Hadamard (cited by [10]) are showing how important is to engage the students in the research tasks. Research assignments advance students and create a more developed way of thinking, awakens them with an innovative and correct mathematical way of looking and thinking in methodological terms.

Having the example of the master degree framework in civil engineering, "the teaching methods used in the mathematic issues are changing over the time, undergoing through consecutive transformations, which are believed to be useful for the improving of the results among the students" [11]. In fact, at civil engineering domain or in other research fields where mathematics is part of the contents, to carry out an investigation requires to take into account various steps and assumptions. In this terms there are some references [10] suggesting the need of considering four key moments, in the process of execution of a mathematical investigation, which are the following listed below. 
The first aspect covers the recognition of the situation, which is the preliminary exploration and the formulation of questions. The second moment refers to the process of formulating conjectures. The third phase includes testing and possible rephrasing of conjectures. The latter refers to argumentation, demonstration and evaluation of the work done during this process. In this process, the scholar needs to plan the classes contents, for each phase of the research subject. In this regard, Ponte [8] says that the scholar can plan the beginning of the investigation, but the end cannot be planed. About this idea some authors [10] are arguing that the development of a research class can be done in the three following stages: (i) introduction of the task, (ii) research, (iii) discussion of the results. However, there are several ways to complete these stages depending on the options of the scholar and the skills of the student.

\section{CONCLUSIONS}

This article has tried to show that the methodological approach of scholars in the domain of mathematics must ensure that whole students in the classroom are in tune, perceiving the meaning and purposes of each research task. The scholar has the role of explain to students in a subjective way what should be done in each research task, allowing them to find an objective conclusion regarding each task. The teacher should be able to find strategies in order to motivate the students to carry out the research tasks, giving some details of how the students should proceed, without showing them the final solution, which must be found by the students.

Among other aspects, such as the student engagement or the scholar skills, in the learning process, the success of a classroom focused on a research topic is related to the familiarity and harmony of students regarding the presented contents of each research task. The scholar should be able to listen, to validate and to include in the tasks contents, whenever is possible, the point of view and the opinions presented by each student, stimulating them to a healthy discussion, considering their backgrounds, skills, or previous knowledge. During this activity, the scholar has the role of a moderator, a referee, understanding the difficulties and the evolutions of the students, in the learning process.

Finally, as this article is intending to show the research process framework has several tasks which are the same despite of the particularity of the subject. Both analysed scientific domains, the urban planning and the mathematics have as research process requirement, a starting point based on the problem formulation or identification. In parallel they both have as the expected final point the systematization of the solution. However, if in the case of the mathematics research field the identification of the solution usually means the end of the process, in the urban planning field this final step of the research is at the same time another starting point, which corresponds to transferring the proposed strategies to the territorial reality. Consequently, the application of the solutions to a case study area, will contribute to foster a monitoring process of the previous proposals, adjusting and adapting the proposed strategies.

\section{ACKNOWLEDGEMENTS}

This work is supported with Portuguese national funds by FCT - Foundation for Science and Technology within the UID/ECI/04082/2013 project and through the Centre of Mathematics and Applications of University of Beira Interior, within the project UID/MAT/00212/2013.

\section{REFERENCES}

[1] A. Virtudes, I. I. Rodrigues et al., "Collaborative learning advancing international students: a multidisciplinary approach", in TEACHING AND LEARNING IN A DIGITAL WORLD, Chapter No: 3, ICL 2017, AISC 715, Springer International Publishing AG, series "Advances in Intelligent Systems and Computing" (ISBN: 978-3-319-73209-1; DOI:10.1007/978-3-319-73210-7_3), 2018.

[2] C. Biase, L. Salvatore, "Up-grading illegal building settlements: an urban-planning methodology" Procedia Environmental Sciences, no. 37, pp. 454-465, 2017.

[3] A. Virtudes, "Good governance principles in spatial planning at local scale", Procedia Engineering, no. 161, pp. 1710-1714, 2016. 
[4] B. Denhardt, J. V. Denhardt, "The new public service: serving rather than steering", Public Administration Review, Washington (Nov. / Dec), vol. 60, no. 6, pp. 549-559, 2003.

[5] K. Frey, "Interactive governance: a conception in order to understand the participatory public management?" (in portuguese) Revista de Sociologia e Política, vol. 1, no. 5, pp. 120-121, 2004.

[6] J. Bourgoin, J. C. Castella, D. Pullar, G. Lestrelin, "Toward a land zoning negotiation support platform: tips and tricks for participatory land use planning in Laos" Landscape and Urban Planning, no. 104, pp. 270-278, 2012.

[7] M. V. Pires, "Investigation tasks in the classroom of mathematics: practices of a mathematics teacher" (in Portuguese), High School of Education, Polytechnic Institute of Bragança, 2011.

[8] J. P. Ponte, "Researching, teaching and learning" (in Portuguese), University of Lisbon, 2003.

[9] J. P. Ponte (org.), "Professional practices of mathematics teachers" (in Portuguese), Education Institute of Lisbon, 2008.

[10] J. P. Ponte et al., "Mathematics researches in the classroom" (in Portuguese), Belo Horizonte, Autêntica Editora, 2003.

[11] A. Virtudes, I. I. Rodrigues, B. Santos, M. Pop, "Teaching Methodologies in Civil Engineering: a multidisciplinary approach", in The National Technical-Scientific Conference, $17^{\text {th }}$ ed.: Modern Technologies for the $3^{\text {rd }}$ Millennium, University of Oradea (Romania), 22-23 March 2018. 